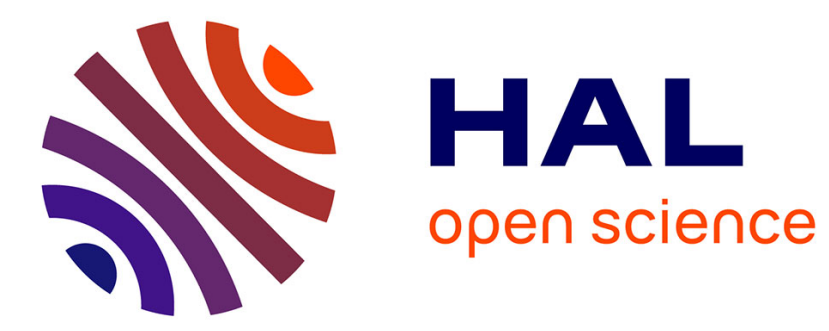

\title{
Strain localization and damage prediction during sheet metal forming
}

Badis Haddag, Farid Abed-Meraim, Tudor Balan

\section{To cite this version:}

Badis Haddag, Farid Abed-Meraim, Tudor Balan. Strain localization and damage prediction during sheet metal forming. International Journal of Material Forming, 2008, 1 (1), pp.229-232. $10.1007 / \mathrm{s} 12289-008-0362-\mathrm{z}$. hal-01205917

\section{HAL Id: hal-01205917 \\ https://hal.science/hal-01205917}

Submitted on 28 Sep 2015

HAL is a multi-disciplinary open access archive for the deposit and dissemination of scientific research documents, whether they are published or not. The documents may come from teaching and research institutions in France or abroad, or from public or private research centers.
L'archive ouverte pluridisciplinaire HAL, est destinée au dépôt et à la diffusion de documents scientifiques de niveau recherche, publiés ou non, émanant des établissements d'enseignement et de recherche français ou étrangers, des laboratoires publics ou privés. 


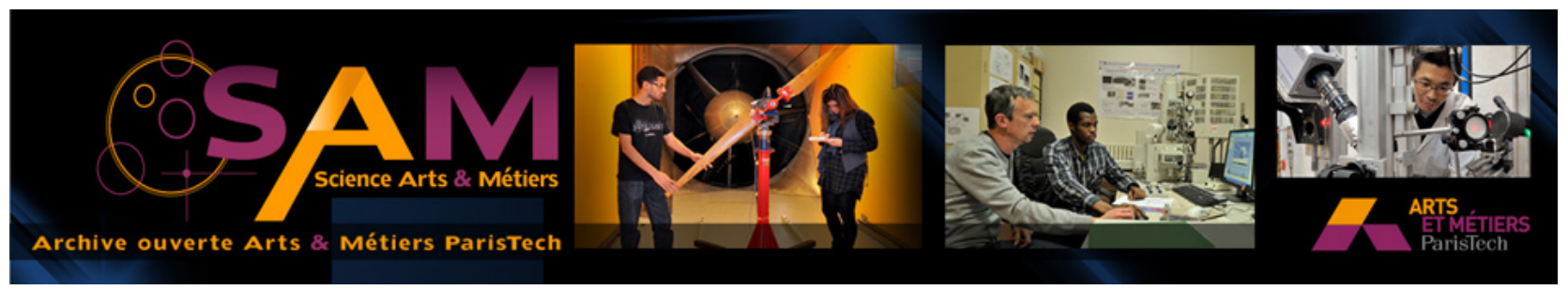

\section{Science Arts \& Métiers (SAM)}

is an open access repository that collects the work of Arts et Métiers ParisTech researchers and makes it freely available over the web where possible.

This is an author-deposited version published in: http://sam.ensam.eu

Handle ID: .http://hdl.handle.net/10985/10187

\section{To cite this version :}

Badis HADDAG, Farid ABED-MERAIM, Tudor BALAN - Strain localization and damage prediction during sheet metal forming - International Journal of Material Forming - Vol. 1, $n^{\circ} 1$, p.229-232 2008 


\title{
Strain localization and damage prediction during sheet metal forming
}

\author{
B. Haddag, F. Abed-Meraim, T. Balan
}

PMM-UMR CNRS 7554, ENSAM de Metz, Arts et Métiers ParisTech

4, rue Augustin Fresnel

57078 Metz Cedex 3

Téléphone: 0387375430

Télécopie : 0387374284

\author{
e-mail: badis.haddag@metz.ensam.fr; \\ farid.abed-meraim@metz.ensam.fr; \\ tudor.balan@metz.ensam.fr
}

ABSTRACT: This work aims to study the strain localization in different sheet metal forming processes by the finite element method using advanced behaviour models. In order to improve the prediction of the formability limit of sheets under forming it is important to consider constitutive models that take into account the degradation of material properties due to large strain localization. For this purpose, an elastic-plastic model has been coupled with the classical damage model of Lemaitre and Chaboche [2,3]. Two hardening models are considered in an attempt to more accurately reproduce the work-hardening phenomenon at large strains. The first one represents the classical cyclic hardening model of Chaboche-Marquis [3,4] while the second corresponds to the so-called dislocation-based microstructural model of Teodosiu and $\mathrm{Hu}[5,6]$. These two models are able to reproduce some transient hardening phenomena at strain path changes - with a better description obtained with the microstructural model. The coupling with damage is carried out within the framework of continuum damage mechanics thanks to the introduction of a scalar variable describing the degradation of the elastic proprieties and consequently softening behaviour when damage occurs. The coupled elastic-plastic damage model is implemented into the Abaqus software using an implicit integration scheme. The resulting code is used for the prediction of forming limit diagrams.

Key words: Hardening, Damage, Strain Localization, Forming Limit Diagram, Finite Element.

\section{INTRODUCTION}

The numerical prediction of metal forming defects is a constant preoccupation both for scientists and industry. With the development of several new grades of sheet metals with high performances (combining ductility and resistance), the study of their formability limit took a great importance, since it contributes to increase the design efficiency by reducing costs and time. Several international conferences organize sessions dealing with this subject (NUMIFORM, ESAFORM, IDDRG, etc). To characterize the formability of sheet metals, Keller (1965) introduced the concept of Forming Limit Diagram. Because the FLDs are shown to be path-dependent, using advanced material behaviour models will contribute to a better prediction of the stress/strain history of the material under complex loading, and thus of the formability limit.

The description of the material behaviour has received considerable attention. For simple applications, the Swift's and Voce's laws are widely used to reproduce the isotropic hardening during monotonic loading paths. However, strain-path changes induce more complex phenomena which must be considered in the constitutive model. In phenomenological approaches, the most advanced models are defined by combining isotropic and kinematic hardening. Since hardening is essentially due to the dislocation microstructure and its evolution for metal sheets, attempts have been made to describe their effect on hardening at a macroscopic scale. Following this approach, Teodosiu and $\mathrm{Hu}$ [5] proposed a microstructurebased model representing not only the monotonic or reverse loading, but also the whole range between the two, including the particular case of orthogonal strain-path. In the current work, the plastic anisotropy induced by hardening has been modelled by both the Teodosiu and $\mathrm{Hu}$ model [6] and the classical cyclic hardening model of Chaboche, combining Armstrong-Frederick's and Voce's laws. However, sheet metal forming involves large plastic deformations which can induce damage due to strain localization. In order to take into account this phenomenon, several theories are proposed by introducing damage in the behaviour models. The 
most used are the Gurson damage theory and the Continuum Damage Mechanics (CDM) introduced by Lemaitre [2]. This last approach is adopted in this paper to couple an elastic-plastic model to damage; especially, the coupling of the advanced hardening model of Teodosiu-Hu with damage. This allows reproducing simultaneously strain-path and softening effects. As applications, stress-strain curves during direct and two-step loading paths as well as FLDs are predicted.

\section{CONSTITUTIVE EQUATIONS}

A material description based on rate equations must respect the principle of objectivity. In finite element implementations, the most commonly used technique is to integrate the rate equations in a frame that rotates with the spin $\mathbf{W}$ (skew-symmetric part of the velocity gradient). This is equivalent to the use of a Jaumann-type stress rate, yet the equations obtained are form-identical to a small strain formulation. Consequently, all the tensor variables below are rotation-compensated with respect to this frame.

This work deals with a general rate-independent, anisotropic, elasto-plasticity model, coupled to an isotropic damage model. More precisely, we consider the physically-based hardening model of Teodosiu and $\mathrm{Hu}$ [6] and the isotropic damage model of Lemaitre [2]. The coupling is carried out through the concept of effective stress:

$$
\tilde{\boldsymbol{\sigma}}=\boldsymbol{\sigma} /(1-d)=\mathbf{C}: \boldsymbol{\varepsilon}^{e}=\mathbf{C}:\left(\boldsymbol{\varepsilon}-\boldsymbol{\varepsilon}^{p}\right)
$$

associated with the principle of strain equivalence [3]. In this equation, $d$ is the continuum damage variable $(d \in[0,1]$, with $d=0$ for a safe material and $d=1$ for a fully damaged one). This is a scalar variable thus damage is assumed isotropic, while $\boldsymbol{\sigma}$ is the stress tensor in the damaged material and $\tilde{\boldsymbol{\sigma}}$ is the stress tensor in an equivalent undamaged material. This is the classical framework of continuum damage mechanics.

\subsection{Basic equations of the coupled model}

The linear elasticity law with damage reads:

$$
\boldsymbol{\sigma}=(1-d) \mathbf{C}: \boldsymbol{\varepsilon}^{e}=(1-d) \mathbf{C}:\left(\boldsymbol{\varepsilon}-\boldsymbol{\varepsilon}^{p}\right)
$$

In our case, the yield condition is written in the following form (Hill'48 criterion):

$$
F=\sqrt{\left(\tilde{\boldsymbol{\sigma}}^{\prime}-\mathbf{X}\right): \mathbf{M}:\left(\tilde{\boldsymbol{\sigma}}^{\prime}-\mathbf{X}\right)}-Y \leq 0
$$

where $\tilde{\boldsymbol{\sigma}}^{\prime}=\boldsymbol{\sigma}^{\prime} /(1-d)$ is the deviatoric effective stress, $Y$ describes the isotropic hardening and $\mathbf{X}$ the kinematic hardening.

The associated flow rule reads:

$$
\dot{\boldsymbol{\varepsilon}}^{p}=\dot{\lambda} \frac{\partial F}{\partial \boldsymbol{\sigma}}=\frac{\dot{\lambda}}{(1-d)} \frac{\mathbf{M}:\left(\tilde{\boldsymbol{\sigma}}^{\prime}-\mathbf{X}\right)}{\tilde{\tilde{\sigma}}}=\frac{\dot{\lambda}}{(1-d)} \mathbf{V}
$$

\subsection{Hardening models}

The macroscopic hardening models are based on a set of internal variables, describing the isotropic and kinematic hardening. The microstructural hardening model of Teodosiu and $\mathrm{Hu}$ is described in detail in $[5,6]$. This model makes use of four internal variables: $\mathbf{X}$ and $R$ are the classical back-stress and isotropic hardening variables, while $\mathbf{S}$ is a fourth order tensor describing the directional strength of the planar persistent dislocation structures and $\mathbf{P}$ is a second order dimensionless tensor describing the polarity of these structures. $\mathbf{S}$ is further decomposed along the current plastic strain-rate direction into an active part $S_{D}$ and a latent part $\mathbf{S}_{L}$. In general, kinematic hardening models often use the direction $\mathbf{N}$ of plastic strain-rate or the direction $\mathbf{n}$ of deviatoric stress. For a plasticity model coupled with damage, these quantities are defined as:

$$
\tilde{\mathbf{N}}(d)=\frac{\dot{\boldsymbol{\varepsilon}}^{p}}{\left|\dot{\boldsymbol{\varepsilon}}^{p}\right|}=\frac{\mathbf{M}:\left(\tilde{\boldsymbol{\sigma}}^{\prime}-\mathbf{X}\right)}{\left|\mathbf{M}:\left(\tilde{\boldsymbol{\sigma}}^{\prime}-\mathbf{X}\right)\right|}, \quad \tilde{\mathbf{n}}(d)=\frac{\left(\tilde{\boldsymbol{\sigma}}^{\prime}-\mathbf{X}\right)}{\tilde{\tilde{\sigma}}}
$$

The model equations are kept identical, except that the directions $\mathbf{N}$ and $\mathbf{n}$ are being replaced with their "effective" counterparts $\tilde{\mathbf{N}}$ and $\tilde{\mathbf{n}}$. The main evolution equations of the Teodosiu model become:

$$
\begin{aligned}
& \dot{R}=C_{R}\left(R_{\text {sat }}-R\right) \dot{\lambda}=H_{R} \dot{\lambda} \\
& \dot{\mathbf{X}}=C_{X}\left(X_{\text {sat }} \tilde{\mathbf{n}}-\mathbf{X}\right) \dot{\lambda}=\mathbf{H}_{X} \dot{\lambda} \\
& \dot{S}_{D}=C_{S D}\left[g\left(S_{\text {sat }}-S_{D}\right)-h S_{D}\right] \dot{\lambda}=H_{S_{D}} \dot{\lambda} \\
& \dot{\mathbf{S}}_{L}=-C_{S L}\left(\frac{\left|\mathbf{S}_{L}\right|}{S_{\text {sat }}}\right)^{n_{L}} \mathbf{S}_{L} \dot{\lambda}=\mathbf{H}_{S_{L}} \dot{\lambda} \\
& \dot{\mathbf{P}}=C_{p}(\tilde{\mathbf{N}}-\mathbf{P}) \dot{\lambda}=\mathbf{H}_{P} \dot{\lambda}
\end{aligned}
$$

where the decomposition of the $\mathbf{S}$ variable becomes:

$\mathbf{S}=S_{D} \tilde{\mathbf{N}} \otimes \tilde{\mathbf{N}}+\mathbf{S}_{L}$

Thus, although the coupling with damage modifies the original equations, their mathematical structure remains identical to their uncoupled form. This property is very useful for the numerical implementation of the model into a finite element code. 


\subsection{Damage evolution law}

Several damage evolution laws are proposed in literature for ductile fracture, especially for sheet metals. The evolution law of the damage variable $d$ is assumed of the following form:

$\dot{d}= \begin{cases}\frac{1}{(1-d)^{\beta}}\left(\frac{Y^{e}-Y_{i}^{e}}{S}\right)^{s} \dot{\lambda}=H_{d} \dot{\lambda} & \text { if } Y^{e} \geq Y_{i}^{e} \\ 0 & \text { otherwise }\end{cases}$

The scalar quantities $s, S, \beta$ and $Y_{i}^{e}$ are material parameters, while $Y^{e}=\frac{1}{2} \boldsymbol{\varepsilon}^{e}: \mathbf{C}: \boldsymbol{\varepsilon}^{e}$ is the elastic strain energy release rate given for linear elasticity by

$$
Y^{e}=\frac{J_{2}^{2}}{2 E}\left[\frac{2}{3}(1+v)+3(1-2 v)\left(\frac{\tilde{\sigma}^{s}}{J_{2}}\right)^{2}\right]
$$

where $\tilde{\sigma}^{s}=\frac{1}{3} \operatorname{tr}(\tilde{\boldsymbol{\sigma}})$ is the hydrostatic effective stress, while $J_{2}=\sqrt{\frac{3}{2} \tilde{\boldsymbol{\sigma}}^{\prime}: \tilde{\boldsymbol{\sigma}}^{\prime}}$ is the von Mises equivalent effective stress.

\section{APPLICATIONS}

In this section, the capability of the proposed approach to predict different characteristics of the stress-strain relationship due to strain-path changes and damage is investigated. Its potential to simultaneously reproduce transient features of the hardening and the softening due to damage is investigated by means of rheological test simulations. Then, a strain localization analysis is performed. This study allows highlighting the capability of the proposed approach to predict the FLDs.

\subsection{Rheological test simulations}

Several direct and sequential loadings are considered for the investigation of the constitutive model. These are regular in-plane loading cases for sheet metal rheological testing, regularly used for the experimental and numerical assessment of the FLDs using various models. The calculations are fully three-dimensional. Four monotonous tests are selected: uniaxial tensile test, plane strain tensile test, simple shear test and balanced biaxial tensile test.

The material under investigation here is a dual phase high strength steel. Its elastic-plastic properties are given in [1]. Only the damage parameters are reported hereafter. Four sets of parameters are considered for the damage law, corresponding to very different damage evolutions; these parameters are reported in Table 1. The four sets are generated by considering activation of damage with the beginning of plasticity or not (i.e. the damage threshold parameter $Y_{i}^{e}=0$ or $\left.\neq 0\right)$ and by considering two different strain levels at failure (i.e. "early" or "delayed" failure).

Table 1: The parameters of damage law corresponding to the four cases - dual phase steel.

\begin{tabular}{lllll}
\hline $\begin{array}{l}\text { Damage } \\
\text { activation }\end{array}$ & \multicolumn{2}{l}{ Without threshold } & \multicolumn{2}{l}{ With threshold } \\
\hline $\begin{array}{l}\text { Damage } \\
\text { completion }\end{array}$ & $\begin{array}{l}\text { Delayed } \\
\text { Set 1 }\end{array}$ & $\begin{array}{l}\text { Early } \\
\text { Set 2 }\end{array}$ & $\begin{array}{l}\text { Delayed } \\
\text { Set 3 }\end{array}$ & $\begin{array}{l}\text { Early } \\
\text { Set 4 }\end{array}$ \\
\hline$Y_{i}^{e}(\mathrm{MPa})$ & 0 & 0 & 1.66 & 1.3 \\
$S$ & 9 & 20 & 0.5 & 0.5 \\
$S$ & 0.5 & 0.01 & 0.5 & 0.6 \\
$\beta$ & 5 & 5 & 15 & 30 \\
\hline
\end{tabular}

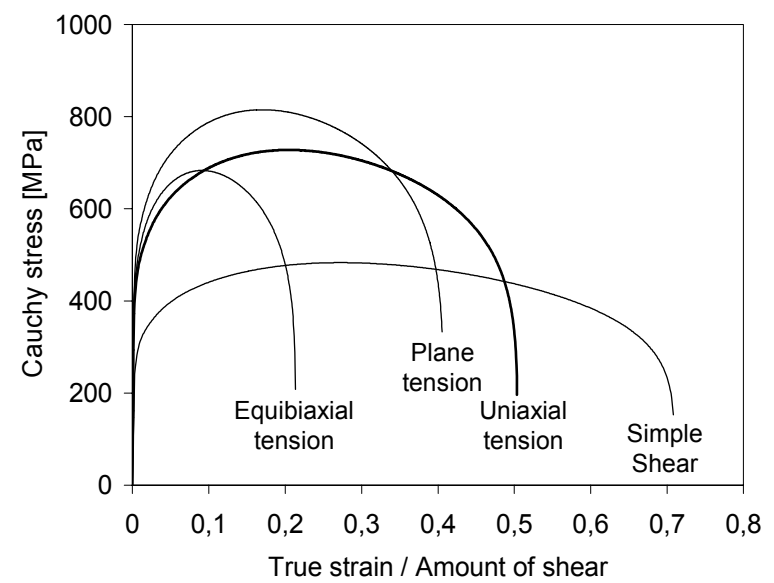

Fig. 1. Different loading path simulations (without threshold) for direct loading

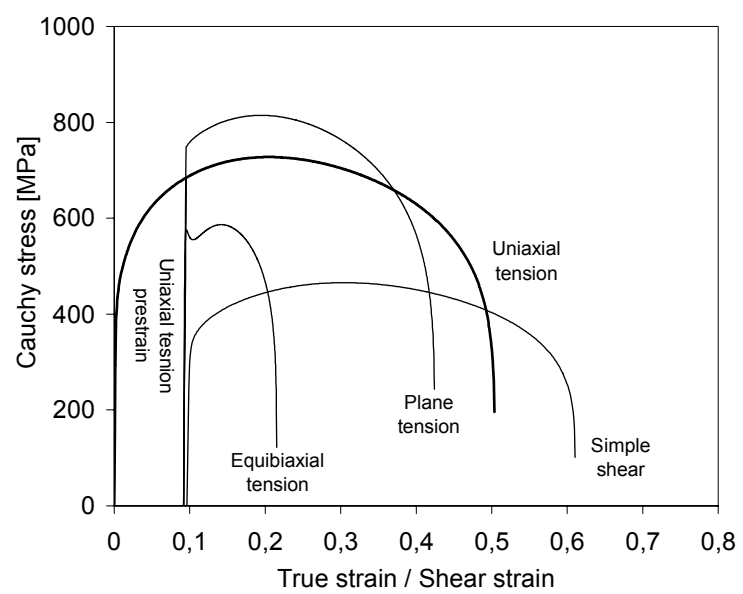

Fig. 2. Different loading path simulations (without threshold) after a uniaxial tensile pre-strain.

The stress-strain curves corresponding to the four monotonous tests are represented in figure 1 . The figure shows the capability of the coupled model to predict the softening phenomenon due to damage 
and underlines the impact of the threshold parameter $Y_{i}^{e}$ on the results. The other damage parameters are set so that the stress-strain curve drops at the same strain level in the case of uniaxial tension. However, the three other curves are very different in the two cases.

Figure 2 shows the results of two-step sequential tests for the case when the damage activates at the beginning of plasticity. The effects of strain-path changes are clearly captured - as shown e.g. at the beginning of the equibiaxial tension after uniaxial tension pre-strain. On the other side, the coupling with the damage model introduces a softening behaviour.

\subsection{Forming Limit Diagram prediction}

The FLDs for the considered dual phase steel in direct and sequential paths are represented in the following figures.

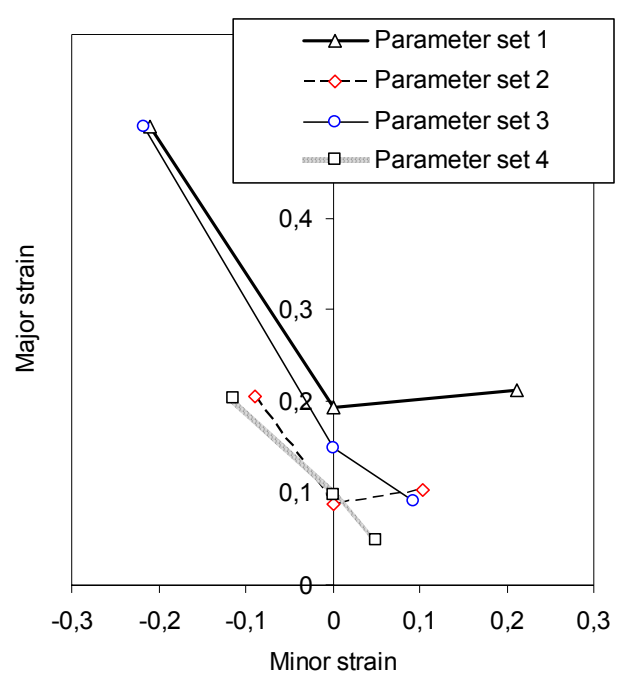

Fig. 1. FLDs predicted for different sets of parameters of the damage law for the considered dual phase steel.

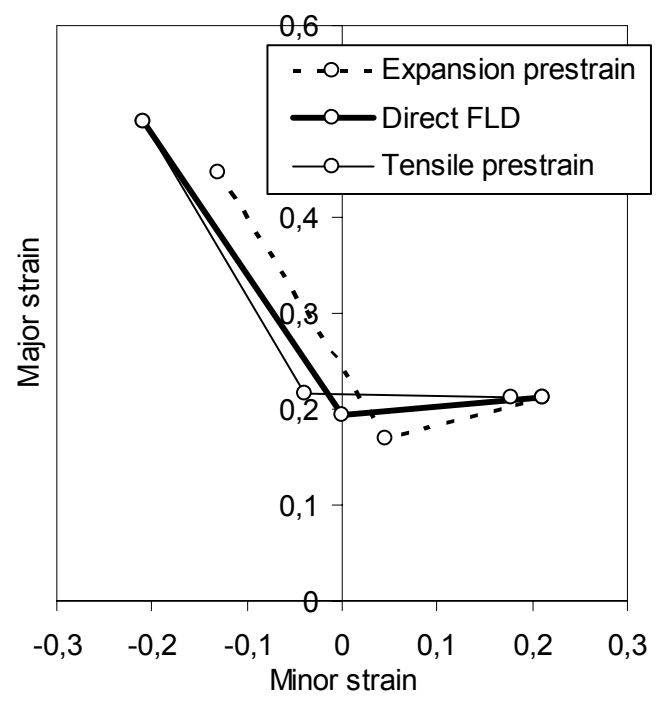

Fig. 2. Effect of tensile and expansion pre-strains on the FLD predicted for the set 1 of parameters of the damage law.

\section{CONCLUSIONS}

An advanced anisotropic elastic-plastic model has been coupled with an isotropic damage model and accurately implemented into a finite element code. The whole of the equations is formulated within the large deformation framework, since sheet metals undergo large strains during forming. A robust numerical integration of the behaviour model has been performed by using an implicit integration scheme and implemented into a finite element code. Direct and sequential rheological tests have been simulated. As a main result, the proposed hardeningdamage coupling allows for the reproduction, simultaneously, of strain-path changes and softening effects. Also, these first numerical applications reproduce the experimental trends in terms of Forming Limit Diagrams.

The modelling framework will thus be further generalized to more complex damage models and their numerical implementation in a fully implicit way. The model can be applied for the prediction of strongly nonlinear FLDs (i.e. with continuous strainpath change), as well as strain localization predictions in finite element simulations of complex forming processes.

\section{REFERENCES}

1. Haddag B., Abed-Meraim F., Balan T., Strain localization analysis using large deformation anisotropic elasto-plastic model coupled with damage. III European Conf. on Computational Mechanics Solids, Structures and Coupled Problems in Engineering, C.A. Mota Soares et al. (eds.) Lisbon, in CD-ROM, (2006) 1-14

2. Lemaitre J., Continuous damage mechanics model for ductile fracture. Journal of Engineering Material and Technology (1985) 107, Issue 1, 83-89

3. Lemaitre J., Chaboche J.L., Mécanique des matériaux solides. Editions Dunod, Paris, (1986)

4. Marquis, D., Modélisation et identification de l'écrouissage anisotrope des Métaux. PhD thesis, University Paris 6, France (1979)

5. Teodosiu C., Hu Z., Evolution of the intragranular microstructure at moderate and large strains: Modeling and computational significance. In: Simulation of Materials Processing: Theory, Methods and Applications. Numiform'95 Proceedings, (1995) 173-182

6. Teodosiu, C., Hu, Z., Microstructure in the continuum modelling of plastic anisotropy. In: $19^{\text {th }}$ Riso International Symposium on Materials Science, Proceedings, Roskilde, (1998) 149-168 